\title{
Assessing sustainable development across Moldova using household and property composition indicators
}

\author{
Richard R. Shaker ${ }^{\text {a, }}$, Igor G. Sirodoev ${ }^{\text {b }}$ \\ ${ }^{a}$ Department of Geography \& Environmental Studies, Ryerson University, Toronto, Ontario, Canada \\ ${ }^{\mathrm{b}}$ Faculty of Natural and Agricultural Sciences, Ovidius University, Constanta, Romania
}

\section{A R T I C L E I N F O}

Article history:

Received 31 October 2015

Available online 7 April 2016

\section{Keywords:}

Additive approach

Local scale

Multi-metric index

Regional development

Sustainable development assessment

Sustainable development planning

\begin{abstract}
A B S T R A C T
Societies are committing themselves to sustainable development by attempting to improve environmental quality, social equity, and economic welfare. As such, there continues a plea for holistic development assessment across scales; however there remains no ideal technique for achieving sustainability on neither regional nor local scale. This paper approaches this problem by constructing a multi-metric assessment system for evaluating development patterns across the Republic of Moldova. The objectives of this study were: (1) to produce a local multi-metric index that captures the three major dimensions of sustainable development for Moldova; (2) to quantitatively evaluate the interrelatedness of sub-metrics used for creating the local composite index of sustainable development; and (3) to visualize and interpret spatial patterns of sustainable development across Moldova. A local sustainable development index (LSDI) was produced using household and property composition indicators from a 2005 demographic and health survey for the Republic of Moldova. Total sample size and aggregated spatial reference was 11,066 households and 399 geographic locations, respectively. The LSDI used a 15 submetric optimum, equal weighting, 1-5 ordinal scale standardization, and additive construction. Spearman's rank correlation coefficient analysis was used to evaluate sub-metric quantitative relationships, and local Moran's I-test to interpret geographic patterns of sustainable development. Results revealed that a wealth sub-index had greatest collinearity with other sub-metrics. Geographically, Moldova's improved sustainability levels were found in large urban areas, suggesting needed prioritization of development resources to the hinterland. For regional sustainable development assessments, this approach provides the transferability to other locally referenced datasets throughout the world.
\end{abstract}

(๑) 2016 Elsevier Ltd. All rights reserved.

\section{Introduction}

Making progress towards sustainability is more important now than ever. Humanity is enduring a period of unprecedented change driven largely by exponential population growth and a demand for improved material well-being. Anthropogenic stressors have continued to hinder Earth's life-supporting ecosystems, and these stressors will likely intensify as population growth and consumption patterns increase (Weinzettel, Hertwich, Peters, Steen-Olsen, \& Galli, 2013). Human population has grown exponentially since the Industrial revolution of the late 1700s (Wu, 2008), and some countries (e.g., India) are projected to see this geometric

\footnotetext{
* Corresponding author.

E-mail addresses: rshaker@ryerson.ca (R.R. Shaker), ingvarri@gmail.com (I.G. Sirodoev).
}

progression into the next century. Global population is now estimated to reach 8.1 billion by 2025 and 9.6 billion by 2050 (UN, 2014), while 2100 projections could surpass 12 billion (Gerland et al., 2014). Recently researchers have argued that environmental degradation is not due to overpopulation as much as it is point and nonpoint pollution and overconsumption of resources by the rich (Hughes \& Johnston, 2005; Weinzettel et al., 2013). Specifically, an increased demand for fuels, fiber, food, and construction supplies have metabolized Earth's natural resources, ultimately causing a projected $70 \%$ increase in global carbon footprint when comparing 2004 to 2050 (Weinzettel et al., 2013).

Besides environmental consequences of consumer behaviors, major global challenges remain between social groups and the interaction between societies and nature (Clark \& Dickson, 2003; Griggs et al., 2013; Kates et al., 2001). Although recent improvements have been recorded, in 2011 close to 14.5 percent of the word's population was classified as living in extreme economic 
poverty (less than US $\$ 1.25$ a day), and lack access to natural resources to meet fundamental needs (WBG, 2014). In regards to climate change, statistical projections reveal that developing nations will remain most vulnerable to its associated risks (Houghton, 2009; Stocker et al., 2013; Vermeulen, Campbell, \& Ingram, 2012). It is in these countries that infrastructure, educational resources, disaster response, access to healthcare, basic survival necessities, and progress to other sustainability goals are diminished, therefore they are more at risk for associated climate change impacts. Griggs et al. (2013) reiterated that biophysical stability must integrate any future United Nations targets to fight poverty and secure human well-being in the new geological epoch, the Anthropocene.

In 2012, the United Nations Conference on Sustainable Development (Rio+20) was held to: 1 ) provide a 20-year follow-up to the 1992 Earth Summit; 2) celebrate the 10th anniversary of the 2002 World Summit on Sustainable Development; and 3) to create a set of sustainable development goals that would follow-up the 2015 Millennium Development Goals deadline. As with other global conferences on sustainability, Rio +20 was focused on operationalizing sustainable development goals at local scales (UNCSD, 2012). Sustainable development is the balanced use of Earth's natural resources while meeting humanity's present and indefinite future socioeconomic needs (WCED, 1987). More than 190 countries have now devoted themselves to sustainable development by incorporating some form of improvement to economic welfare, social equity, and environmental quality into their everyday activities (UNCSD, 2012). That said, there exist no 'ideal' planning tools for accomplishing sustainability neither on the regional nor local scales (Keiner, 2006), and most applied sustainable development studies remain at the international scale (Shaker \& Zubalsky, 2015). To end, policy makers have been encouraging scientists to develop new techniques that integrate qualitative and quantitative methods for local and regional sustainable development planning (Grosskuth, 2007).

In Chapter 40.4 of Agenda 21 the need for indicators was articulated: "indicators of sustainable development need to be developed to provide solid bases for decision making at all levels and to contribute to a self-regulatory sustainability of integrated environment and development systems" (UN, 1992: 346). As part of this process, numerous private and public institutes have developed a plethora of development measurements for making progress towards sustainability. Although often considered poor at helping make decisions at margins (Rogers, Jalal, \& Boyd, 2008), indicators, and their composite version indices, can be used to analyze, communicate, simplify, and quantify complex and complicated information into meaningful results (Pollesch \& Dale, 2015; Singh, Murty, Gupta, \& Dikshit, 2012). Indicators and indices are increasingly accepted as useful tools for policy-making because they convey information on a country's performance towards their specific goals within the three major divisions of sustainability (social equity, economic welfare, environmental quality) (Shaker \& Zubalsky, 2015). Finally, the proper choice of development metrics is fundamental for examining progress towards sustainability (Bossel, 1999; Prescott-Allen, 2001); however, understanding their inputs, weaknesses, strengths, scale-dependencies, data needs, before using them is even more important (Morse \& Fraser, 2005; Ness, Urbel-Piirsalu, Anderberg, \& Olsson, 2007; Parris \& Kates, 2003).

To be successful at sustainable development planning at any scale, suitable methods and guidelines are required (Keiner, 2006). To date, much of the discussion on measuring progress towards sustainability is limited to academia (Hezri \& Dovers, 2006), and most research has been predominately subjective rather than quantitatively supported (Phillips, 2015). In response, this paper intends to demonstrate an applied, and quantitatively supported, approach for comprehensively evaluating sustainable development across the Republic of Moldova for the first time. This will be achieved through the application of data collected through the use of a 2005 demographic and health survey for that country. The objectives of this paper were three-fold: (1) to produce a local multimetric index that captures the three major dimensions of sustainable development for Moldova; (2) to quantitatively evaluate the interrelatedness of sub-metrics used to create the local composite index of sustainable development; and (3) to visualize and interpret spatial patterns of sustainable development in the Republic of Moldova. By investigating a multi-metric index of sustainable development quantitatively and spatially, it is hoped that this research will help operationalize local sustainability assessments. This study also aims to deliver sustainability planners and scientists an applied example and transferable technique for calculating a country's local patterns of development during sustainability assessments.

\section{Study area and historical context}

The Republic of Moldova (Fig. 1) is an ideal location for conduction a local applied sustainable development study, as no previous regional comprehensive assessment exists for this country. The geographic area once known as Moldova was significantly larger than the area comprising the present day Republic of Moldova. Currently, the Republic of Moldova is located between the Prut and Dniester/Nistru Rivers to the west and east, respectively, Ukraine to the north and southeast, and Romania to the southwest. Moldova is landlocked between the Ukraine and Romania, occupies $33,846 \mathrm{Km}^{2}$ of land, and has over 4.3 million people (2010 census); $42 \%$ of its inhabitants live in urban areas. The capital of Moldova, Chişinău, found in the south central part of the country, has remained settled since the 15th century and is the largest city. As of the local 2014 census, Chişinău's city population was just under 500,000 with about 5400 people $/ \mathrm{km}^{2}$. Bălţi is the third largest city by population after Tiraspol and Chișinău, but remains the second most important city in the country and is located in the north central. As of the local 2014 census, Bălţi's city population was just over 140,000 .

In June 1940, according to the Molotov-Ribbentrop pact, the present day region of Moldova was annexed from Romania by the Union of Soviet Socialist Republics (USSR) to form the Moldavian Soviet Socialist Republic (MSSR). During World War II, the MSSR area fell back to Romania and then was annexed for the final time to the Soviet Union. After the 1944 annexation of Moldova to the USSR, the progression of creating a uniformed, patriotic, and Soviet-cultured Empire began. This process officially introduced the Cyrillic alphabet and Russian language into everyday lifereplacing the traditional Latin alphabet and Romanian language. During this time, cultural re-education (e.g., removal of religion and Romanian holidays) was set into action manipulating the indigenous people of Moldova to change their native ways. Severe economic recession, transplanting of native Russians, and slow nation building shortly followed. Soviet rule promoted urbanization and industrialization, even though Moldova was traditionally agricultural. Soviet governmental methods soon changed with the introduction of "glasnost" (openness) by Soviet President Mikhail Gorbachev. This new policy set the stage for Moldova's future independence.

On 27 August 1991, after a failed coup in Moscow resulted in the ousting of Gorbachev from power and the political collapse of the USSR, the Moldavian Parliament and the Republic's General Assembly declared independence. After declaring its independence, the Republic of Moldova was marked by conflict and turmoil. Early interests in reunifying greater Romania and the presence of a large 


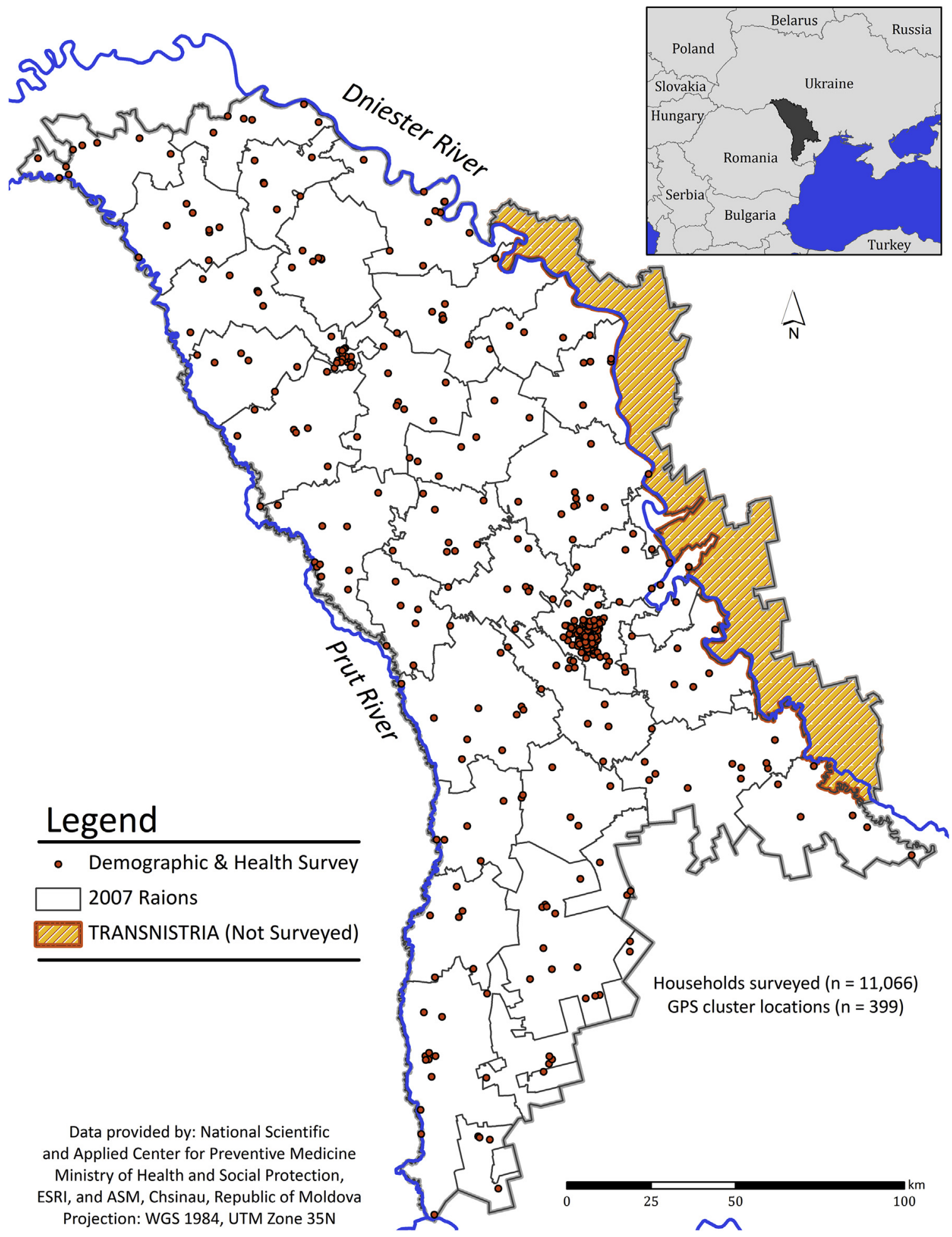

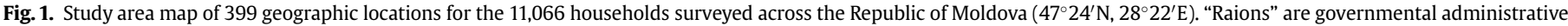
zones similar to counties in other countries.

ex-Soviet (Russian) military force provoked a short civil war in 1992-1993. This civil war led to the separation of Transnistria from the rest of the Republic. This area, east of the Dniester/Nistru River, still has sensitive ethnicity and language issues. The demographic breakdown of Transnistria is about 65 percent Romanian, 14 percent Ukrainians, 13 percent Russian, and the rest Gagauz, Jewish, and Bulgarian. Tiraspol is the capital of Transnistria, which is not recognized by the several governments of the world.

Significant social (i.e., human trafficking), economic (i.e., weapons manufacturing), and environmental (i.e., ground water pollution) issues have been linked to the Republic of Moldova. Much of the issues in the Republic of Moldova are linked to lack of 
jobs and money. Moldova is the poorest country in Europe and has suffered a nearly 65 percent decline in income since its independence. From 1991 to 2000 the Republic of Moldova recorded only one year of positive GDP growth. Sporadic and ineffective law enforcement, combined with economic and political uncertainty, and outstanding disputes with international investors, continues to discourage direct foreign investment. To aid in local sustainable development goals, more advanced counties have tried to improve development conditions in the Republic of Moldova. In example, in 2005 the U.S. provided roughly $\$ 27$ million in assistance to the Republic of Moldova to alleviate issues associated to post-landprivatization, promote democratic institutions and civil societies, improve law enforcement and border control, and combat human trafficking. To date, many of these issues remain unresolved in the Republic of Moldova.

\section{Material and methods}

\subsection{Moldova demographic and health survey}

Household and property composition data, from a 2005 Moldova Demographic and Health Survey (MDHS, 2006), were used to create a multi-metric local sustainable development index (LSDI) for capturing the three aspects of sustainability. The MDHS (2006) was in direct response to setting a baseline and measuring progress towards achieving the United Nations Millennium Development Goals. Over a two-month period from June 13th to August 18th, 2005, Moldova's first nationally representative demographic and health sample survey of over 11,000 households was conducted to inventory the population and health status in Moldova. The MDHS (2006) sampled over 11,000 households and were spatially referenced to 400 sample locations throughout the Republic of Moldova (excluding Transnistria region). The survey includes detailed information on fertility levels, marriage, sexual activity, nutritional status of women and young children, childhood mortality, and household structure, property, and composition. Additional features of the MDHS (2006) include the collection of information on international emigration, language preference for reading, and domestic violence.

The MDHS (2006) is based on a representative probability sample of over 11,000 households. This sample was intended to allow separate urban and rural estimates for key population and health indicators (e.g., infant mortality, fertility, contraceptive prevalence). Transnistria, the semiautonomous district in the eastern part of the country holding 15 percent of Moldova's population was not entered in the sample. The MDHS (2006) utilized a two-stage sample design. The first step involved selecting sample location zones (Global Positioning System; GPS centroids) pertinent to the 2004 Moldova Population and Housing Census. A total of 400 GPS areas in Moldova were selected from the master sampling framework. GPS zones for urban and rural domains (233 urban and 167 rural) were chosen using systematic sampling with probabilities proportional to the 2004 census distribution, and consequently the final household distributions were too (MDHS, 2006). A complete household listing procedure was carried out from April to late May 2005 in all 400 GPS zones in order to provide a sampling framework for the second stage selection of households (MDHS, 2006). The second stage selection involved the systematic picking of households from a complete listing of all households in each of the 400 GPS areas. The sample "take" in both urban and rural zones was 30 households, which would make a total sample size of 12,000 households throughout the Republic of Moldova. Due to a geographic coordinate error found within the MDHS (2006) dataset employed, one GPS location and its associated households were removed from the database. Any records missing indicator data were also removed from the database. A total of 11,066 households corresponding to 399 GPS locations remained and were utilized during the forthcoming local spatial sustainable development assessment (Fig. 1).

The household questionnaire was used to list all the regular members and visitors in the selected households and to identify women and men who were suitable for the individual interview. Basic information was collected on the attributes of each person listed, including their sex, age, education, and relationship to the head of the household (MDHS, 2006). In addition, a distinct listing on former household members who had emigrated abroad was gathered. The household questionnaire was also designed to collect information on characteristics of the household's dwelling unit, which included the source of water, type of toilet facilities, materials used for the floor and roof of the house, and ownership of various durable goods (MDHS, 2006). Along with the geographic locations of all cities greater than 50,000 in population, the aforementioned demographic and health database was used to create 15 sub-metrics for the multi-metric LSDI. The selection, justification, and assessment of the 15 MDHS variables are explained in detail within the forthcoming section.

\subsection{Calculation: local sustainable development index}

A number of different approaches have been established for measuring progress towards sustainability, and many are presently in use across temporal and spatial scales (see Singh et al., 2012). However, despite it being over two decades since Agenda 21 called for local sustainable development measuring initiatives, there remains no consensus regarding how best to design index models or use them (Wilson, Tyedmers, \& Pelot, 2007). Jepson (2004) stated that while communities are engaging in the enactment of policies and techniques that are consistent with sustainable development, few local initiatives show evidence of successfully integrating all three spheres of sustainability. Additionally, although practitioners and policy-makers have embraced indicators across spatial scales, they are seldom used due to lack of accessibility, understanding, and usefulness to those who manage at local scales (Carruthers \& Tinning, 2003; Innes \& Booher, 2000; Reed, Dougill, \& Baker, 2008). It was suggested by Maclaren (1996) that good sustainable development measures are: scientifically valid, representative of a broad range of conditions, responsive to change, relevant to the needs of potential users, based on accurate and accessible data, based on data that are available over time, comprehensive, understandable by potential users, comparable with indicators developed in other jurisdictions, cost-effective to collect and use, attractive to the media, and unambiguous. A method is presented hereafter to produce a local multi-metric index for evaluating spatial patterns of sustainable development across the Republic of Moldova.

The local sustainable development index (LSDI) created for the Republic of Moldova used a 15 sub-metric optimum, which crossed 10 categories designed to capture the "triple bottom line." Constrained to data availability, the 10 groupings were: household abundance, structural composition, goods production, transportation, utility services, income, technology, public health, psychology, and education (Table 1). Although other methods should be considered (see Singh et al., 2012), expert judgment was used herein to balance social, economic, and environmental needs- and select sub-indicator directionality-for reaching sustainability in Moldova. The 2007 United Nations report, Indicators of Sustainable Development: Guidelines and Methodologies, was used as a reference for selecting and justifying sub-metrics. Additionally, the 2008 update of the Official List of Millennium Development Goals Indicators was referenced during this phase of the research. 
Table 1

Local sustainability development index (LSDI) metrics and scoring criteria adapted for spatial assessment across the Republic of Moldova.

\begin{tabular}{|c|c|c|c|c|c|c|c|c|}
\hline \multirow[t]{2}{*}{ Category } & \multirow[t]{2}{*}{ Metrics } & \multirow[t]{2}{*}{ Metric code } & \multirow{2}{*}{$\begin{array}{l}\text { Fig. } 2 \\
\text { map \# }\end{array}$} & \multicolumn{5}{|l|}{ Scoring criteria } \\
\hline & & & & 1 & 2 & 3 & 4 & 5 \\
\hline Household abundance & 1. Number of household members & HA-1 & 1 & Less & & & & More \\
\hline \multirow[t]{2}{*}{ Structural composition } & 2. Residence type and number of rooms used for sleeping & SC-1 & 2 & Single-family/more & & & & Multi-family/less \\
\hline & 3. Main roof, wall, and floor material & SC-2 & 3 & Weak/thin & & & & Strong/thick \\
\hline \multirow[t]{2}{*}{ Goods production } & 4. Amount of land owned by household & GP-1 & 4 & Less & & & & More \\
\hline & 5. Amount livestock, herds, or farm animals & GP-2 & 5 & Less & & & & More \\
\hline \multirow{2}{*}{ Transportation } & 6. Has vehicle(s) (truck/car; motorcycle/scooter) & TR-1 & 6 & More & & & & Less \\
\hline & 7. Distance to nearest city and capital (Chisinau) & TR-2 & 7 & More & & & & Less \\
\hline \multirow[t]{2}{*}{ Utility services } & 8. Type of cooking fuel & SE-1 & 8 & Solid fuel & & & & Elect./gas \\
\hline & 9. Water heat, refrigerator, t.v., and washing machine & SE-2 & 9 & More & & & & Less \\
\hline Income & 10. Wealth Index & WE-1 & 10 & Low & & & & High \\
\hline Technology & 11. Computer, mobile phone, microwave, and DVD/VCR & TE-1 & 11 & Less & & & & More \\
\hline \multirow[t]{2}{*}{ Public health } & 12. Access to improved water source & PH-1 & 12 & Less/worse & & & & More/better \\
\hline & 13. Access and type of sanitation facility & $\mathrm{PH}-2$ & 13 & Less/worse & & & & More/better \\
\hline Psychology & 14. Number of household members outside country & PS-1 & 14 & More & & & & Less \\
\hline Education & 15. Head of household education level & ED-1 & 15 & Less & & & & More \\
\hline
\end{tabular}

Scoring: 5, near reference; 3 , significant deviation from reference; 1 , strong deviation from reference.

Often an indicator directionally (i.e., positively) represents two goals of sustainable development but seldom can it capture all three aspects simultaneously. According to Campbell (1996: 296) this is the "planner's triangle," and "the center cannot be reached directly, but only approximately and indirectly, through a sustained period of confronting and resolving the triangle's conflicts." This is problematic when creating composite measures for reaching sustainability at any spatial scale, thus having a clear overarching goal is key for guiding the multi-metric index (MMI) construction. As in this study, when sub-metric discrepancy occurs, the directionality that improves global life-supporting ecosystems should be chosen. Justification for prioritizing ecological (biosphere) well-being comes from Shaker (2015b) findings that Europe's life-supporting ecosystems are significantly more compromised than human welfare, and Butchart et al. (2010) four decades of biodiversity loss at the global scale. With the number of development indices overwhelming to scientists, policymakers, and planners, there remains a need to create holistically accurate, justifiably simple, and operational indices that address a country's specific needs and development goals (Shaker, 2015a). That said (Böhringer \& Jochem, 2007), found that country-specific indices often fail to accurately conduct the three fundamental scientific steps during index formation: normalization, weighting, and aggregation.

For accuracy and computational simplicity, ease of comprehension and replication, and due to a large sample size $(n=11,066)$, the following MMI formula details were used: 15 indicators, 1 to 5 ordinal scale standardization from a best-case reference value; equal weighting between sub-metrics; and an overall additive construction to create the LSDI for Moldova (Table 2). Thus, the potential range for the Moldova LSDI was 15-75 with greater values equaling improved sustainable development conditions.

Although the 15 sub-metrics of LSDI can represent different development goals, for organizational purposes, each one is assigned to its primary dimension of sustainability (social equity, economic welfare, environmental quality). The six indicators that more directly represented social equity were: type of cooking fuel (SE-1); computers, mobile phone, microwave, and DVD/VCR (TE-1); access to improved water source (PH-1); access and type of sanitation facility (PH-2); number of household members outside the country (PS-1); and head of household education level (ED-1). The two indicators that more directly represented economic welfare were: main roof, wall, and floor material (SC-2); and a "Wealth Index" (WE-1). The Wealth Index, constructed using household assets and precalculated within the MDHS (2006) dataset, was developed and tested in a number of countries in relation to inequalities in household income, use of health services, and health outcomes (Rutstein, Johnson, \& Gwatkin, 2000). Note that the Wealth Index was found to be statistically consistent with other expenditure and income measures (Rutstein, 1999). The seven indicators that more directly represented environmental quality were: number of household members (HA-1); residence type and number of rooms used for sleeping (SC-1); amount of land owned by household (GP-1); amount of livestock, herds, or farm animals (GP2); has vehicles(s) truck, car, motorcycle, and scooter (TR-1); distance to nearest city and capital (Chişinău) (TR-2); number of appliance(s) water heater, refrigerator, television, and washing machine (SE-2). The spatial distribution of each standardized LSDI sub-metric is illustrated here (Fig. 2).

\subsection{Data analysis}

After design and calculation of the multi-metric LSDI for Moldova, an ex post facto analysis was conducted to: (i) depict the overall numerical distribution of LSDI; (ii) assess relationships between sub-metrics; and (iii) illustrate the local spatial patterns of sustainable development for regional assessment. Specifically, a histogram and a boxplot were created to explore and express the overall numerical frequency of LSDI for Moldova. Next, the nonparametric Spearman's rank (rho) correlation coefficient test $\left(r_{s}\right)$ was used to measure numerical dependence between LSDI metavariables. Finally, the local index of spatial association (LISA) Anselin (1995) Moran's I-test was used to illustrate geographic patterns of LSDI. Along with the construction of a LSDI for Moldova, these aforementioned techniques were deemed appropriate for completing the study's objectives.

There are two critical issues regarding the simultaneous use and inclusion of indicators: (a) correlations among metric values, and (b) which indicators are substitutable when necessary (Singh et al., 2012). A two-tailed Spearman's rank (rho) correlation coefficient test $\left(r_{s}\right)$ was used to analyze relationships between the 15 established sub-indices for the 11,066 households used in this study $(n=11,066)$. Spearman's rank coefficient is a common statistic used for measuring the collinearity between two variables. This nonparametric correlation coefficient test deemed appropriate for evaluating numerical dependence of both continuous and discrete values, including ordinal values (Lehman, 2005). This common correlation coefficient tests was used as a descriptive measure of relative strengths of relationships between LSDI sub-metrics after 
Table 2

Local sustainability development index (LSDI) metric values for spatial assessment across the Republic of Moldova.

\begin{tabular}{|c|c|c|c|c|c|c|c|}
\hline \multirow[t]{2}{*}{ Metrics } & \multirow[t]{2}{*}{ Metric code } & \multirow[t]{2}{*}{ Fig. 2 map\# } & \multicolumn{5}{|c|}{ Scoring criteria } \\
\hline & & & 1 & 2 & 3 & 4 & 5 \\
\hline 1. Number of household members & HA-1 & 1 & $<2.5$ & $2.5-4.8$ & $4.9-7.2$ & $7.3-9.6$ & $>9.6$ \\
\hline 2. Residence type and number of rooms used for sleeping & SC-1 & 2 & $>10.4$ & $7.9-10.4$ & $5.3-7.8$ & $2.7-5.2$ & $<2.7$ \\
\hline 3. Main roof, wall, and floor material & SC-2 & 3 & $<22.9$ & $22.9-24.6$ & $24.7-26.4$ & $26.5-28.2$ & $>28.2$ \\
\hline 4. Amount of land owned by household & GP-1 & 4 & $<60$ & $60-118$ & $119-177$ & $178-236$ & $>236$ \\
\hline 5. Amount livestock, herds, or farm animals & GP-2 & 5 & $<114$ & $114-227$ & $228-340$ & $341-453$ & $>453$ \\
\hline 6. Has vehicle(s) (truck/car; motorcycle/scooter) & TR-1 & 6 & $>12$ & $10.0-12.0$ & $7.0-9.0$ & $4.0-6.0$ & $<4$ \\
\hline 7. Distance to nearest city and capital (Chisinau) & TR-2 & 7 & $>180,194$ & $135,147-180,194$ & $90,099-135,146$ & $45,049-90,098$ & $<45,049$ \\
\hline 8. Type of cooking fuel & SE-1 & 8 & $<7$ & 7 & 8 & 9 & $>9$ \\
\hline 9. Water heat, refrigerator, t.v., and washing machine & SE-2 & 9 & $>4$ & 4 & 3 & 2 & $<2$ \\
\hline 10. Wealth Index & WE-1 & 10 & 1 & 2 & 3 & 4 & 5 \\
\hline 11. Computer, mobile phone, microwave, and DVD/VCR & TE-1 & 11 & $<1.6$ & $1.6-3.2$ & $3.3-4.9$ & $5.0-6.6$ & $>6.6$ \\
\hline 12. Access to improved water source & PH-1 & 12 & $<25.2$ & $25.2-46.4$ & $46.5-67.6$ & $67.7-88.8$ & $>88.8$ \\
\hline 13. Access and type of sanitation facility & $\mathrm{PH}-2$ & 13 & $<7.2$ & $7.2-10.4$ & $10.5-13.6$ & $13.7-16.8$ & $>16.8$ \\
\hline 14. Number of household members outside country & PS-1 & 14 & $>4.9$ & $3.8-4.9$ & $2.5-3.7$ & $1.3-2.4$ & $<1.3$ \\
\hline 15. Head of household education level & ED-1 & 15 & $<1.3$ & $1.3-2.4$ & $2.5-3.6$ & $3.7-4.8$ & $>4.8$ \\
\hline
\end{tabular}

Scoring: 5, near reference; 3 , significant deviation from reference; 1 , strong deviation from reference.

raw indicators were ordinal scale standardized. Like other correlation coefficient tests (i.e., Pearson's), Spearman's rank coefficient range from -1 to +1 . When interpreting this statistic, correlation values can be classified into very negative $(-1.0$ to $<-0.75)$, negative $(-0.75$ to $<-0.5)$, neutral $(-0.5$ to +0.5$)$, positive $(>+0.5$ to +0.75$)$, very positive $(>+0.75$ to +1.0$)$. The statistical package JMP (ver. 11) (SAS, 2013) was employed during the descriptive and correlation analyses.

In applied sustainable development studies, it is imperative to take into account spatial autocorrelation. The first law of geography defines that variables nearer in space are more similar (spatial autocorrelated) than variables that are farther apart (Tobler, 1970). Spatial autocorrelated values are regularly found in geographically managed data sets (Legendre \& Legendre, 2012), and can be interpreted as both problematic and beneficial for assessing sustainable development. When conducting traditional inferential parametric tests (i.e., ordinary least squares; OLS regression), spatial nonstationarity is seen as a substantial limitation as it violates the assumption of randomly distributed errors (Dormann et al., 2007). However, one significant benefit of spatial autocorrelation is that it can provide statistically significant meaning to geographical patterns associated with sustainable development (Shaker, 2015b).

For spatial analysis purposes, the multi-metric LSDI produced from 11,066 Moldavian households values were aggregated to the 399 GPS locations. By doing so, this created mean LSDI value for each of the 399 aforementioned spatially referenced centroids. Next, Thiessen polygons, also known as proximity polygons, Delaunay triangulation, or Voronoi diagrams, were generated from the 399 MDHS (2006) sample centroids. For the purpose of this study, Thiessen polygons allowed for a 'neighborhood' definition based on common boundaries between the aforementioned 399 GPS locations. Although averaging LSDI to Thiessen polygons was deemed appropriate for this study, much works remains for guiding aggregation techniques in sustainability assessment (Pollesch \& Dale, 2015). Finally, to visualize and interpret the overall spatial patterns of sustainable development in the Republic of Moldova, local Anselin (1995) Moran's I-test was conducted as an exploratory spatial data analysis (ESDA). This non-stationarity assessment of LSDI used queen contiguity of the 399 Thiessen polygons. Local spatial autocorrelation statistics values vary from each other; however positive scores of local Anselin (1995) Moran's I indicate that a geographic feature has statistically significant $(P<0.05$ level $)$ clustering of neighboring features with similarly high (high-high) or low (low-low) attributed. Outliers are recorded when a high value is surrounded primarily by low values (high-low) or vise-aversa (low-high). Various tools within ESRI (2014) ArcMap 10.2 were employed during this phase of the study.

\section{Results}

\subsection{Descriptive statistics}

The summation of the 15 sub-metrics across 11,066 households revealed varying levels of sustainable development conditions in the Republic of Moldova. The calculated values of LSDI ranged from 36 (very bad) to 64 (very good), while the mean and median were 52.02 and 52, respectively (Fig. 3). When averaging the 11,066 households to the 399 Thiessen polygons mean LSDI values compressed to range from 45.23 (bad) to 58.13 (good). The average value of mean LSDI was 52.22, while the median was recorded as 52. The histogram and boxplot of LSDI revealed a normal (Gaussian) frequency, while mean LSDI values were somewhat bimodal. The spatial distribution of mean LSDI across the 399 Thiessen polygons displayed varying geographic patterns of sustainable development in the Republic of Moldova (Fig. 4).

\subsection{Correlation coefficient analysis}

Spearman's rank correlation coefficients for one sub-metric with the other 14 indicators ranged from -0.64 to +0.70 with varying levels of statistical significance (Table 3). Since no correlation coefficients reported very positive or very negative values, negative $(-0.75$ to $<-0.5)$ or positive $(>+0.5$ to +0.75$)$ correlation coefficients relationships were expounded here. Seven statistically significant relationships were found within the aforementioned negative or positive correlation coefficient ranges. With five scores documented, the Wealth Index (WE-1) exhibited the highest degree of collinearity of all sub-metrics with significant relationships to: access to improved water source (PH-1); computers, mobile phone, microwave, and DVD/VCR (TE-1); head of household education level (ED-1); main roof, wall, and floor material (SC-2); and number of appliances: water heater, refrigerator, television, and washing machine (SE-2). Wealth Index (WE-1) was positively associated to four of these five sub-indicators of sustainable development; however negatively associated with resource consumption through the utility services demand proxy SE-2. A positive correlation coefficient was also recorded between the number 


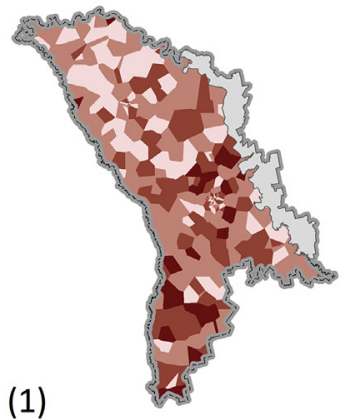

\# Household Members

Mean HA-1 Value

$1.969-2.467$

$1.751-1.968$

$1.561-1.750$

$1.222-1.560$

(6)

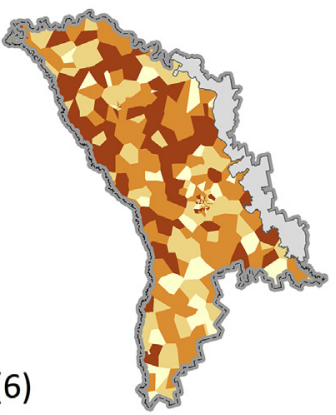

(7)
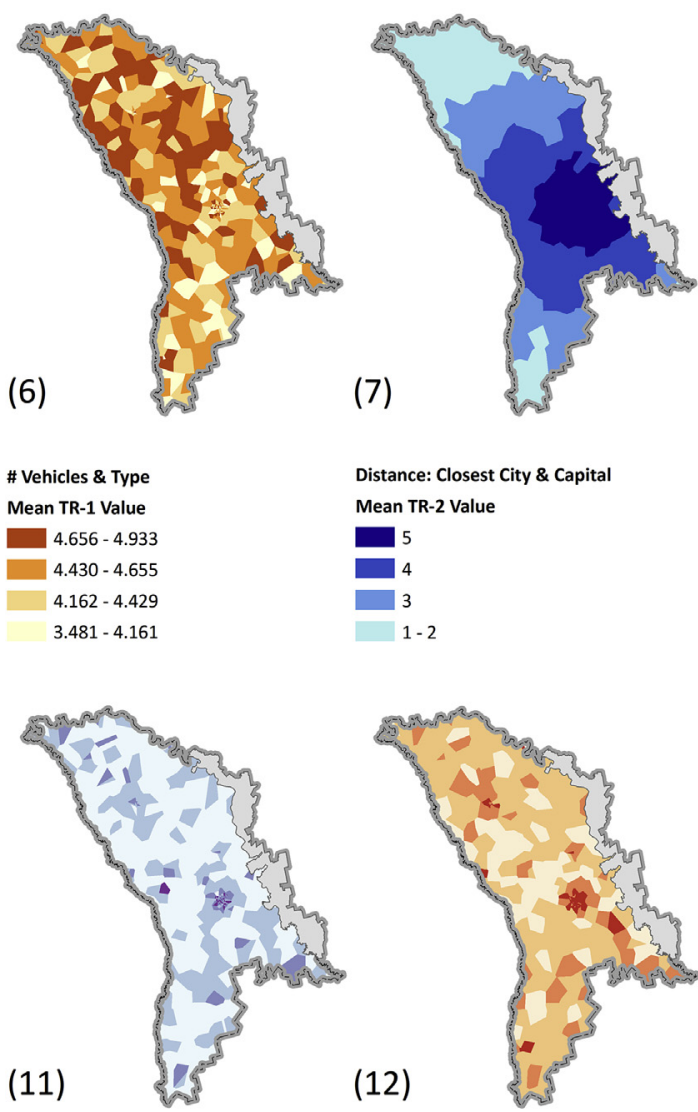

(11)

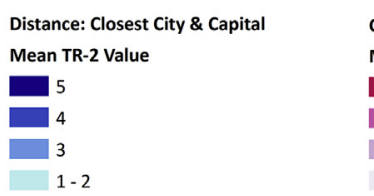

(8)
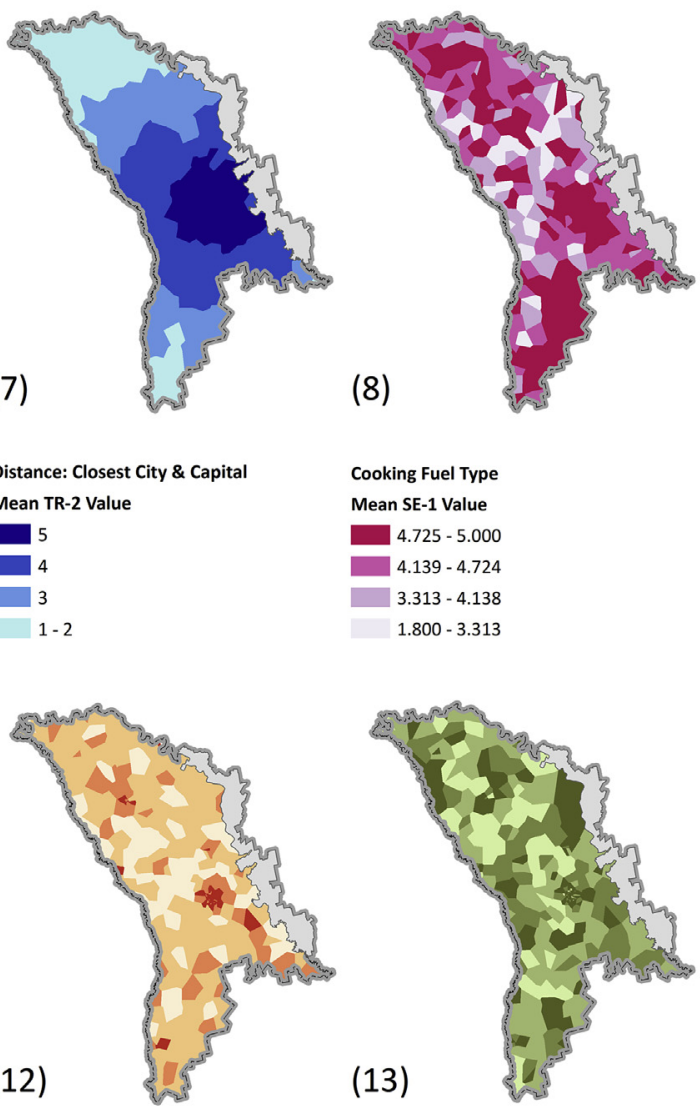

(12)

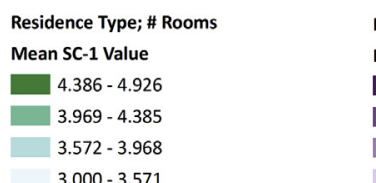

(3)
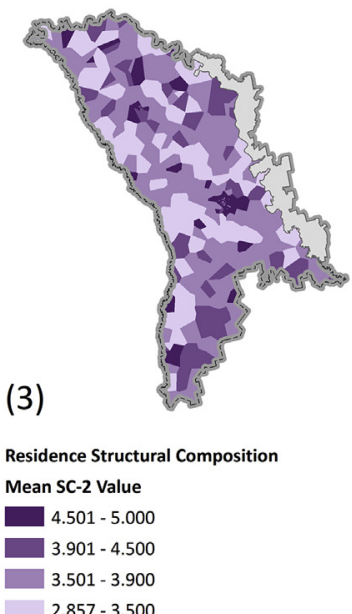

(4)
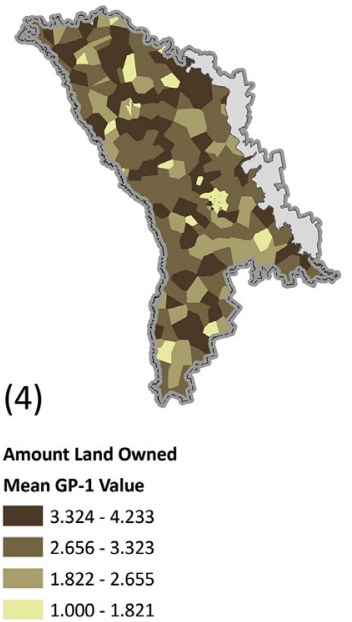

(5)
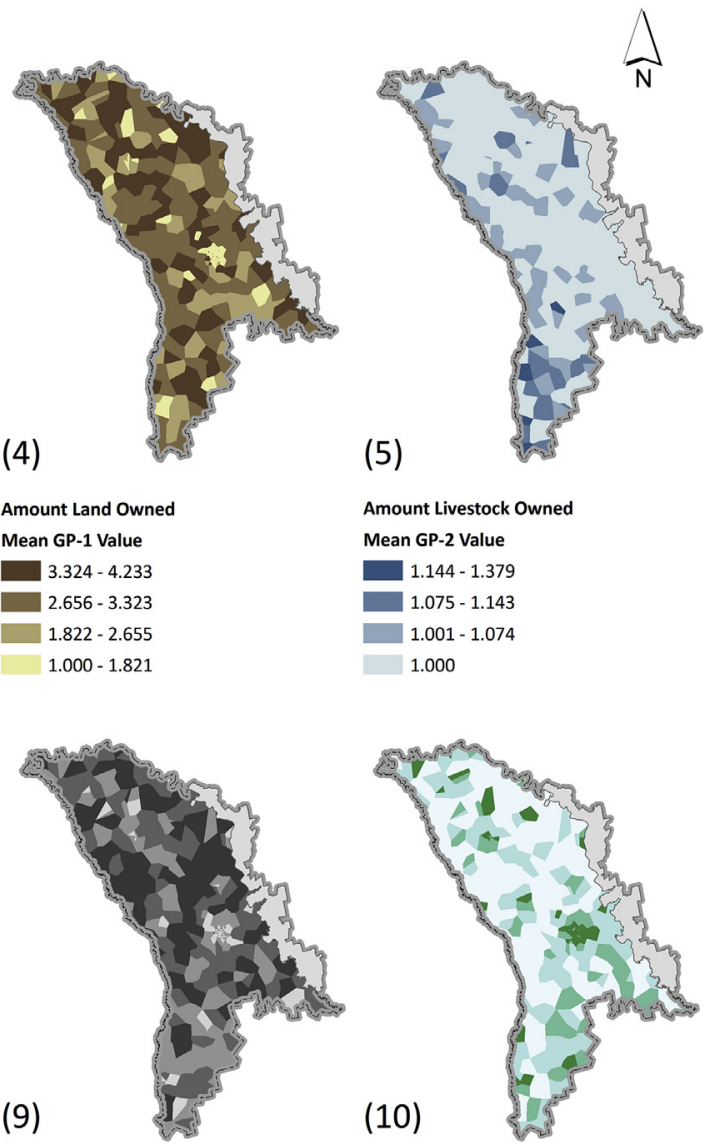

(10)
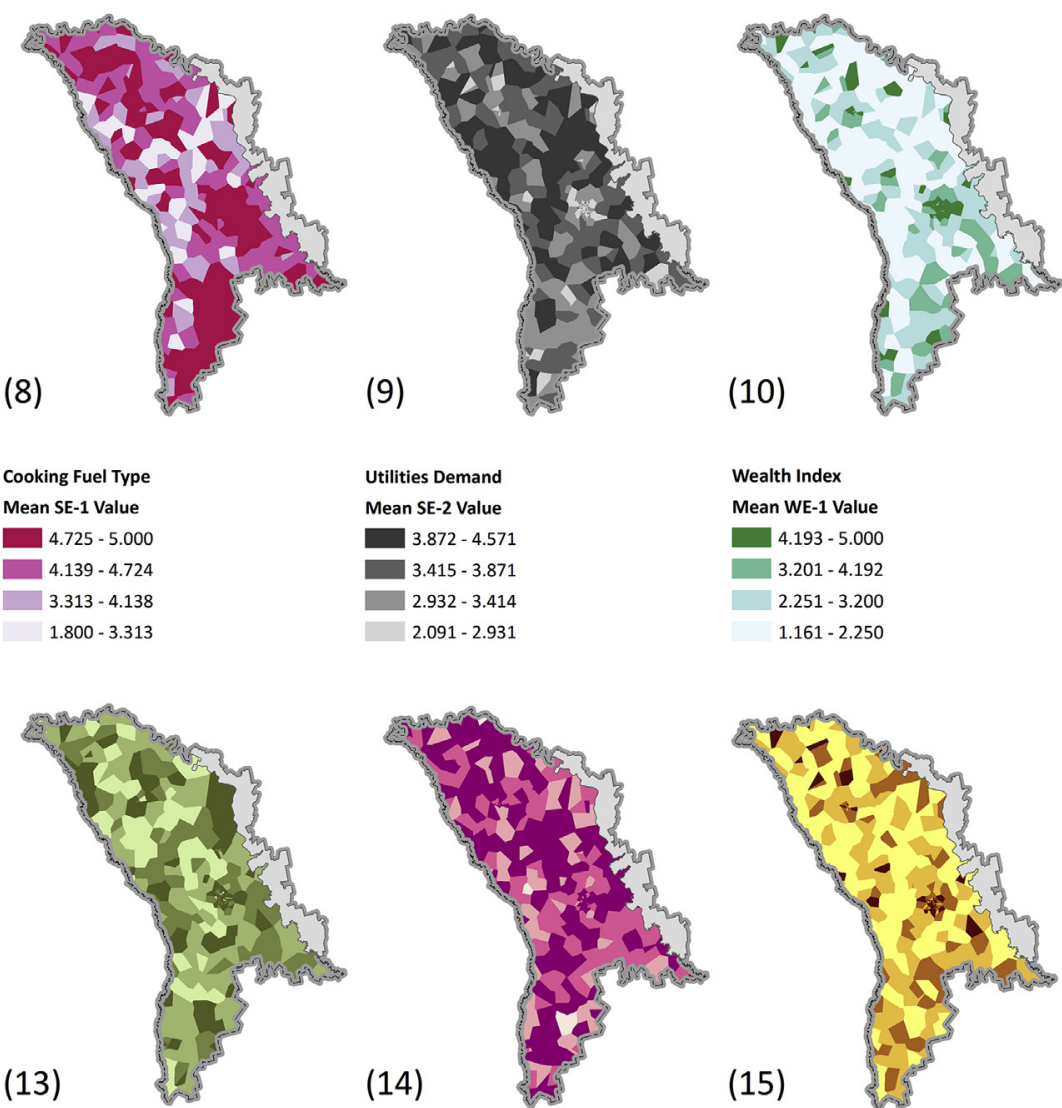

\begin{tabular}{|c|c|}
$\begin{array}{l}\text { Technology } \\
\text { Mean TE-1 Value }\end{array}$ & $\begin{array}{l}\text { Improved Water } \\
\text { Mean PH-1 Value }\end{array}$ \\
\hline $3.001-3.593$ & $4.297-5.000$ \\
\hline $2.572-3.000$ & $3.634-4.296$ \\
\hline $2.260-2.571$ & $3.037-3.633$ \\
\hline $2.000-2.259$ & $1.586-3.036$ \\
\hline
\end{tabular}
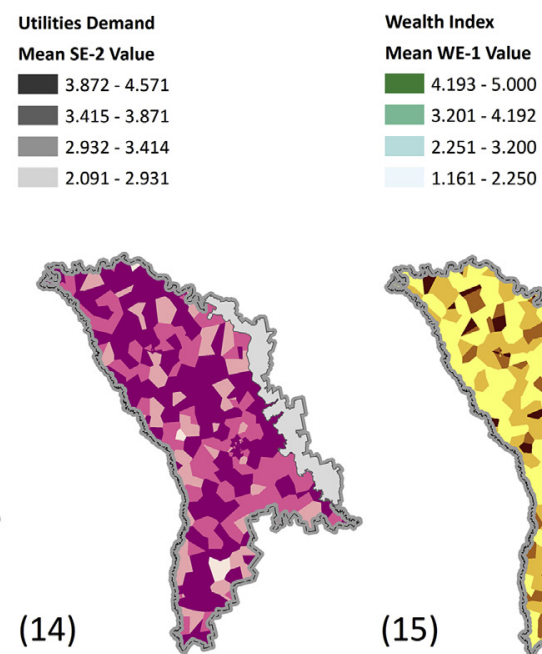

(15)

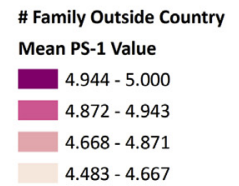

Head of Household Education

Mean ED-1 Value

4.234-5.000

$3.742-4.233$

- $3.277-3.741$

$2.462-3.276$

$1: 5,500,000$

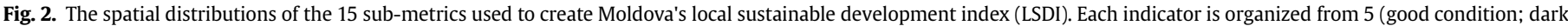

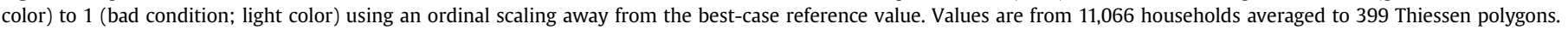


A.

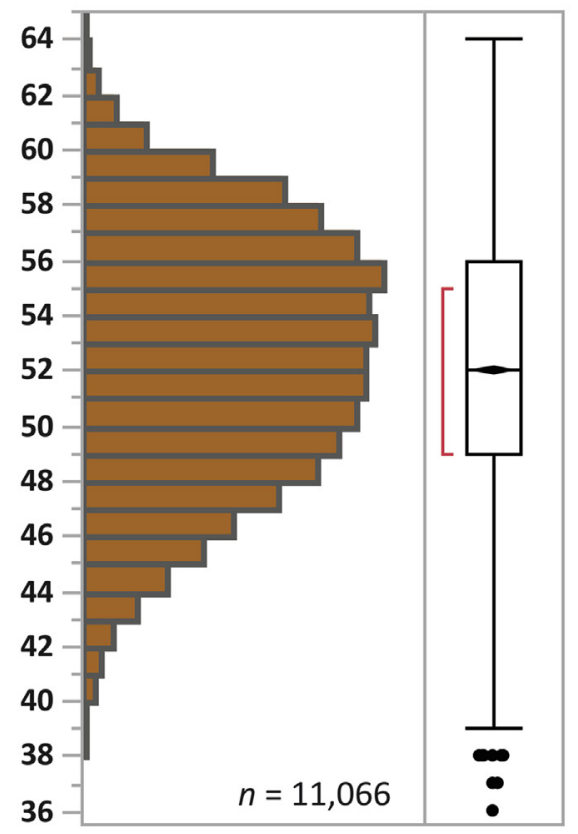

B.

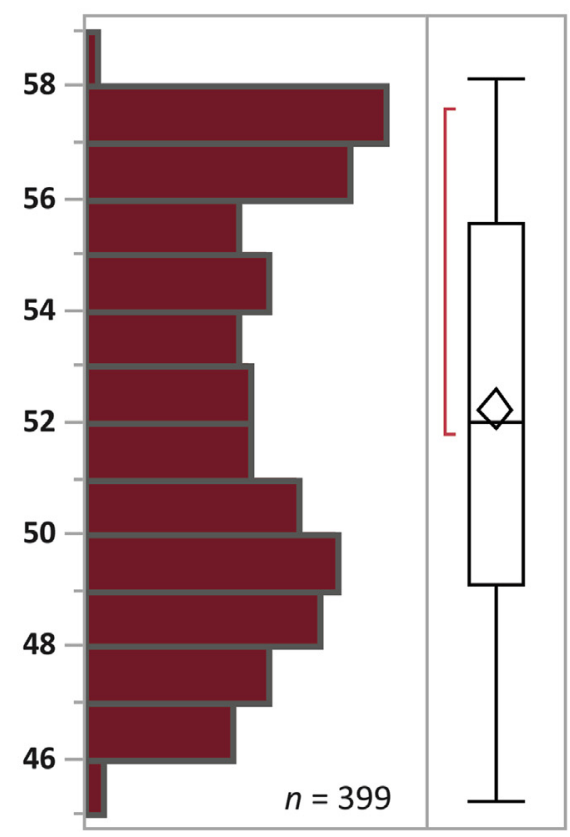

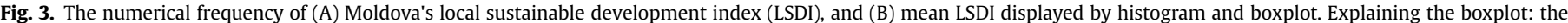

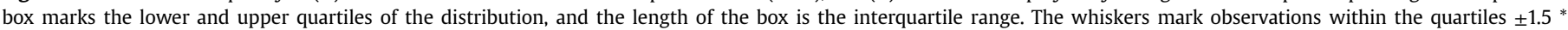
(interquartile range); observations beyond the whiskers are considered outliers.

of household members (HA-1) and the amount of land owned by the household (GP-1). Lastly, a positive statistical relationship was also found between access to improved water source (PH-1) and main roof, wall, and floor material (SC-2).

\subsection{Exploratory spatial data analysis}

When interpreting global Moran's I, mean LSDI had less than $1 \%$ likelihood its spatial pattern was due to random chance. The LISA index, Anselin Moran's I, illustrated statically significant geographical clustering of mean LSDI across the 399 Thiessen polygons (Fig. 5). In general, the highest levels of improved LSDI conditions were found in and contiguous to the city of Chișinău. Other improved sustainable development levels were found in and around Bălţi in the northern center of the country; however these improved values did not render statistically significant spatial clustering here. Outside of urban areas, it is clear that the greatest majority of low LSDI values were found in the northern half of the country. Overall, the geographical patterns of sustainable development in Moldova suggest a current dichotomy between urban and rural settlements. In another specific example, besides a few larger urban settlements, decreased sustainable development conditions can also be found along the entire western border of the country. However, since rural to urban migration is projected to continue well into the next century (Gerland et al., 2014; Wu, 2008), overall improved development conditions can be expected in the Republic of Moldova's future.

\section{Discussion}

\subsection{Patterns of Moldavian development}

This study reveals geographical patterns that reflect the traditional structure of the Moldavian settlement system. Therefore, the findings cannot be understood without some key knowledge of the national settlement system. The Moldavian settlement system has an equally distributed cell-like structure with 32 Raions (districts akin to counties; see Fig. 1) and one autonomous region (Gagauzia) that represent isolated zones directly coordinated by the capital city Chişinău (Sirodoev, 2009). Within the entire country there is just one city, Bălţi, which plays the role of regional coordinator. Bălţi found in the northern $1 / 3$ of the country counterweights that of Chişinău in the south central, and these two cities alone combine to account for roughly $55 \%$ of the total urban population found in Moldova. The spatial patterns of individual sub-metrics helped to identify Moldavian development patterns that could not be found through spatial analysis of the composite LSDI. The sub-indicator distributions (Fig. 2) helped to reveal three main types of geographical patterns: (1) north-south polarization, (2) urban vs. non-urban influenced, and (3) randomly distributed. The north-south polarization can be explained by economic prosperity level, cultural differences, and other geographical factors; however the latter two patterns, urban vs. non-urban influenced and randomly distributed, are mostly related to the cell-like structure of the aforementioned settlement system.

\subsubsection{North-south polarization}

This geographic pattern can be identified by the number of household members (HA-1), amount of livestock, herds, or farm animals (GP-2), number and type of vehicles (TR-1). The northern part of the country has smaller family sizes, improved individual mobility with more per capita vehicles, and less livestock per household. At the same time, the southern part of the country remains more traditional (peasant subsistent) with larger families, fewer automobiles per household, and lifestyles contingent on larger livestock herds (especially sheep). Please note, these north-south polarization patterns are mainly outside cities, as the number of household members and the amount of vehicles per household is fewer in urban areas in comparison to the hinterland. Also note, there is increased access to mass transit within urban 


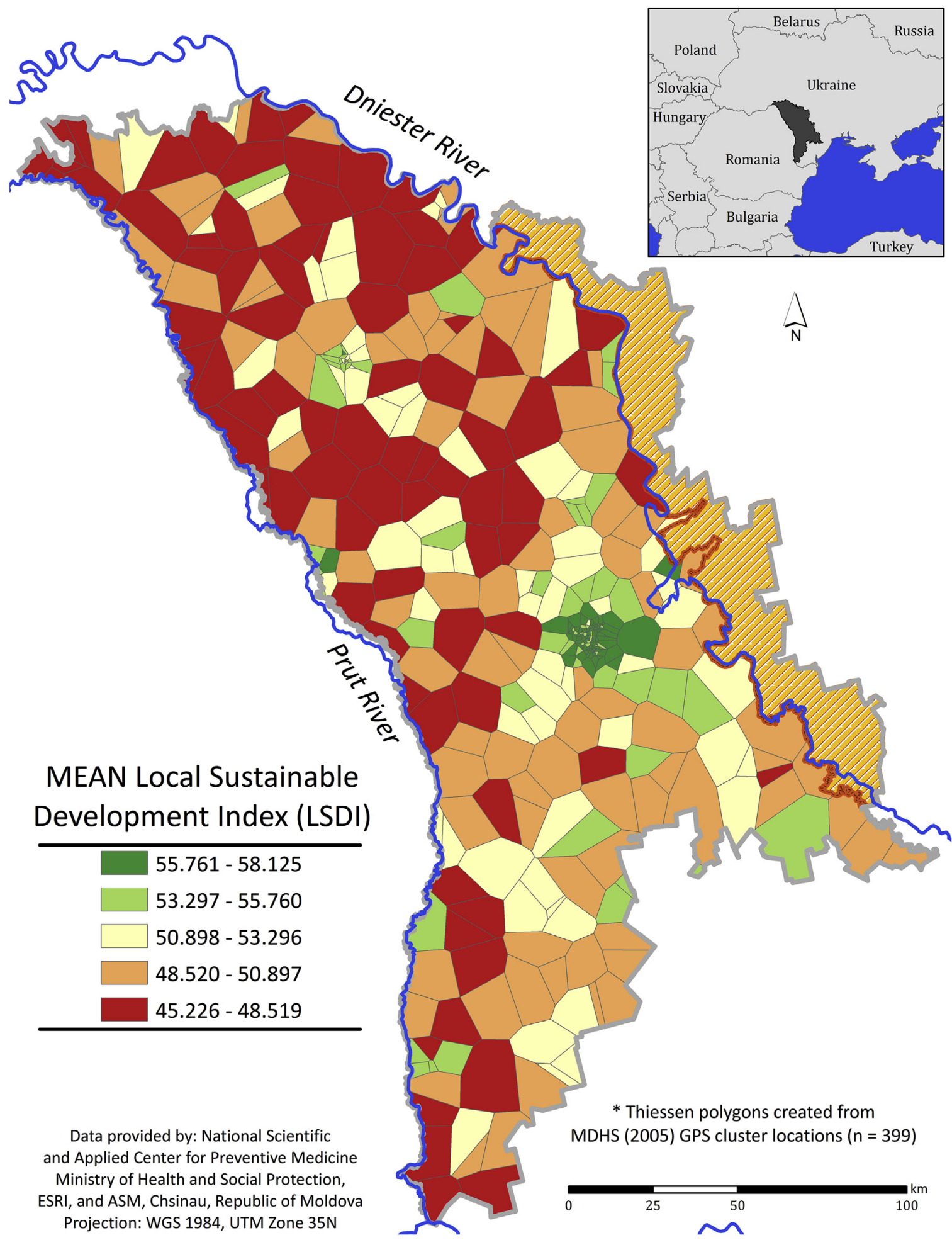

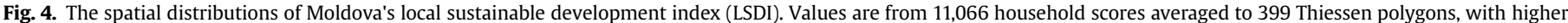
values representing improved development.

areas of Moldova justifying the lack of automobiles per capita there.

\subsubsection{Urban vs. non-urban influenced}

This geographic pattern refers to territories impacted by urban centers in comparison to rural and remote areas. Such development relationships are reflected by: residence type and number of rooms used for sleeping (SC-1); main roof, wall, and floor material (SC-2); the Wealth Index (WE-1); computers, mobile phone, microwave, and DVD/VCR (TE-1); access to improved water source (PH-1); and head of household education level (ED-1). These indicators reflect improved sustainable development conditions within and around urbanized settlements, while decreased levels are found in remote 
Table 3

Spearman's rank correlation coefficients (rho) for the 15 sub-metrics used in the local sustainability development index (LSDI) for the Republic of Moldova.

\begin{tabular}{|c|c|c|c|c|c|c|c|c|c|c|c|c|c|c|c|}
\hline Indicator & HA-1 & SC-1 & SC-2 & GP-1 & GP-2 & TR-1 & TR-2 & SE-1 & SE-2 & WE-1 & TE-1 & PH-1 & PH-2 & PS-1 & ED-1 \\
\hline Fig. 2 map\# & 1 & 2 & 3 & 4 & 5 & 6 & 7 & 8 & 9 & 10 & 11 & 12 & 13 & 14 & 15 \\
\hline HA-1 & 1 & $-0.34^{* *}$ & -0.01 & $0.60^{* *}$ & $0.08^{* *}$ & $-0.24^{* *}$ & 0.02 & $0.05^{* *}$ & $-0.19^{* *}$ & $0.06^{* *}$ & $0.19^{* *}$ & $0.04^{* *}$ & 0.01 & $0.06^{* *}$ & $0.07^{* *}$ \\
\hline SC-1 & & 1 & $0.29^{* *}$ & $-0.31^{* *}$ & $-0.13^{* *}$ & $0.14^{* *}$ & $0.18^{* *}$ & $0.12^{* *}$ & $-0.02^{*}$ & $0.32^{* *}$ & 0.01 & $0.22^{* *}$ & $0.16^{* *}$ & $0.02^{*}$ & $0.14^{* *}$ \\
\hline SC-2 & & & 1 & $-0.42^{* *}$ & $-0.05^{* *}$ & $-0.07^{* *}$ & $0.29^{* *}$ & $0.29^{* *}$ & $-0.35^{* *}$ & $0.70^{* *}$ & $0.27^{* *}$ & $0.51^{* *}$ & $0.44^{* *}$ & 0.01 & $0.35^{* *}$ \\
\hline GP-1 & & & & 1 & $0.04^{* *}$ & 0.01 & $-0.26^{* *}$ & $-0.17^{* *}$ & $0.17^{* *}$ & $-0.49^{* *}$ & $-0.15^{* *}$ & $-0.35^{* *}$ & $-0.28^{* *}$ & $-0.04^{* *}$ & $-0.21^{* *}$ \\
\hline GP-2 & & & & & 1 & $-0.09^{* *}$ & $-0.09^{* *}$ & -0.01 & $-0.03^{* *}$ & $-0.08^{* *}$ & 0.01 & $-0.03^{* *}$ & $-0.05^{* *}$ & -0.01 & $-0.02^{*}$ \\
\hline TR-1 & & & & & & 1 & -0.01 & $-0.16^{* *}$ & $0.37^{* *}$ & $-0.25^{* *}$ & $-0.37^{* *}$ & $-0.18^{* *}$ & $-0.09^{* *}$ & $0.03^{* *}$ & $-0.23^{* *}$ \\
\hline TR-2 & & & & & & & 1 & $0.13^{* *}$ & $-0.20^{* *}$ & $0.42^{* *}$ & $0.18^{* *}$ & $0.34^{* *}$ & $0.20^{* *}$ & $0.03^{* *}$ & $0.21^{* *}$ \\
\hline SE-1 & & & & & & & & 1 & $-0.38^{* *}$ & $0.47^{* *}$ & $0.20^{* *}$ & $0.31^{* *}$ & $0.17^{* *}$ & $-0.04^{* *}$ & $0.26^{* *}$ \\
\hline SE-2 & & & & & & & & & 1 & $-0.64^{* *}$ & $-0.46^{* *}$ & $-0.48^{* *}$ & $-0.30^{* *}$ & $0.06^{* *}$ & $-0.42^{* *}$ \\
\hline WE-1 & & & & & & & & & & 1 & $0.50^{* *}$ & $0.70^{* *}$ & $0.49^{* *}$ & -0.01 & $0.50^{* *}$ \\
\hline TE-1 & & & & & & & & & & & 1 & $0.36^{* *}$ & $0.23^{* *}$ & $-0.03^{* *}$ & $0.35^{* *}$ \\
\hline PH-1 & & & & & & & & & & & & 1 & $0.39^{* *}$ & $0.02^{*}$ & $0.41^{* *}$ \\
\hline PH-2 & & & & & & & & & & & & & 1 & -0.02 & $0.26^{* *}$ \\
\hline PS-1 & & & & & & & & & & & & & & 1 & 0.01 \\
\hline ED-1 & & & & & & & & & & & & & & & 1 \\
\hline
\end{tabular}

Notes: $\mathrm{N}=11,066$; Spearman's (rho) conducted using a two-tailed test.

** Correlation is significant at the 0.01 level.

* Correlation is significant at the 0.05 level.

towns, hamlets, and the rural countryside. Development circumstances diverge quite strongly in some cases, especially those indicators more directly impacted by urban opportunities (e.g., TE-1, PH-1). The distance to nearest city and capital (Chişinău) (TR-2) captures the greatest urban to rural gradient, influencing such things as: access to governmental services, healthcare, and education; transportation cost of good and services; and employment opportunities. The legacy utilities infrastructure stemming outward from Chişinău and Bălţi, along with landscape topography and remnant forestlands, can explain the country-wide zone of inefficient/dirty cooking fuel (SE-1) roughly equidistance between the two coordinating cities. Likewise, the utility services demand proxy, measured through the number of large appliances (SE-2), is highest equidistance between Chişinău and Bălţi, while also elevated in other hinterland locations.

\subsubsection{Randomly distributed}

This geographic pattern was coined due to high fragmentation, relative uniformity, or heterogeneous spatial patterns of development conditions across the country. Although the amount of land owned by household (GP-1) is significantly lower within cities, the overall spatial patterning across Moldova is random. Access and type of sanitation facility (PH-2) is improved within Bălţi and Chişinău, likely due to large-scale waste treatment plants there, but this indicator remains randomly distributed for much of the country. Lastly, the number of household members outside the country (PS-1) varies drastically across Moldavian households with no clear spatial pattern. This phenomenon suggests that economic opportunities are convoluted in Moldova, ultimately causing income-driven emigration to impact many households.

\subsection{Moldova's millennium development goals}

In 1992 the newborn Republic of Moldova, signed the UN Declaration on Environment and Development, assumed it would be part of the global process of switching to a more sustainability sensitive economy. Nonetheless, local scenarios of economic liberalization guided Moldova's very first years of economic transition rather than those of neoliberal economic thought (Sirodoev, 2009). Since 1993, in cooperation with the International Monetary Fund and the World Bank, Moldova began implementing reforms designed to stabilize its macro-economic sectors and create a basic framework for a market economy (i.e., privatization). After the 1998 regional economic crisis, the reforms were designed to rebuild national economic structure in concert with the principles of a market economy. Additionally, in 1998 the work on National Sustainable Strategy within the World Bank project began (Sirodoev, 2009).

The National Strategy on Sustainable development was adopted by Republic of Moldova Parliament in 2000. The same year, the Moldavian government signed the Millennium Declaration, which made sustainability principles and Millennium Development Goals (MDGs) ubiquitous on public agenda for all levels of government regardless of their political orientation. Nonetheless, over the past decade Moldova's economic performance stagnated from lack of policy incentives, ultimately forcing emigration of many working class citizens (Sirodoev, 2009). Further, any source of national economy investment (i.e., World Bank loan) is expected to progressively dry out, which will have a significant impact on all future aspects of sustainable development in Moldova (National Report, 2012). In these circumstances, sticking with Millennium Declaration and negotiation new post-2015 agenda will represent key steps for future economic development. In doing so, the principles of sustainable development must switch from "being on the agenda" to "being the foundation" for new policy development in Moldova.

In the past 15 years, the Republic of Moldova's progress towards MDGs was inconsistent. Some of the targets have been reached before the 2015 deadline, while others are not likely to be achieved within the proposed terms of the post-2015 Development Agenda. Thus, the final targets of the 1st MDG - reduce extreme poverty and hunger - have already been achieved in 2012. According to the data monitored and provided by the National Bureau for Statistics, its indicators for 2013 were significantly below the proposed targets: population living under the absolute poverty line is $12.7 \%$ (target: 20.0\%); and share of population suffering from hunger is $0.3 \%$ (target: $3.5 \%$ ). Emigration is likely to be the main contributor for reducing suffering associated with MDG 1; however regional imbalances remain between rural and urban regions, with significant levels of rural poverty persisting.

The 2nd MDG - achieve universal access to general compulsory education - does not present any threat for Moldova due to inherited features of the Soviet education system. Thus, the final target set for 2015 has been achieved in 2011. However, there is a strong concern caused by huge discrepancies between rural and urban settlements. Besides the formal aspect of the MDGs, the 


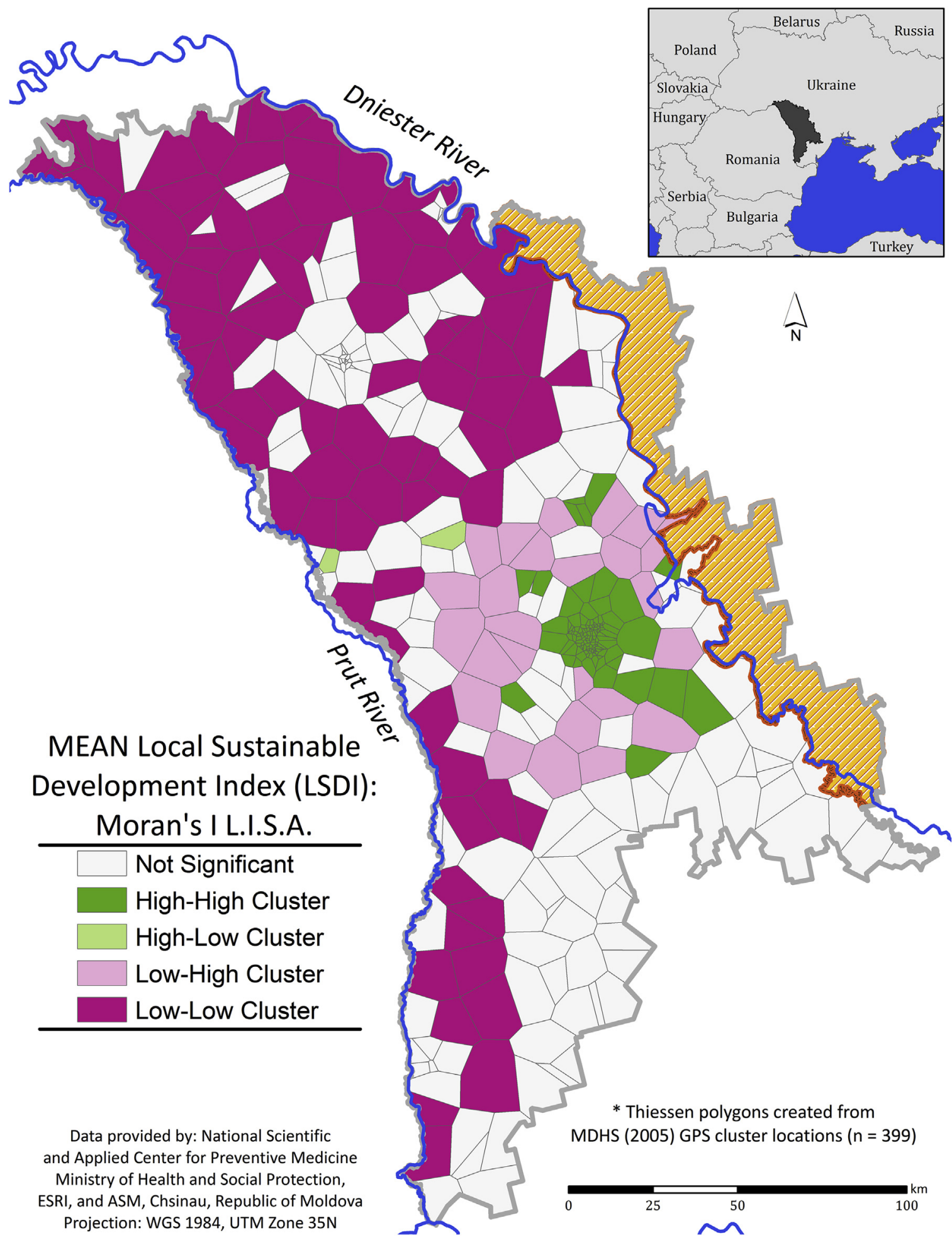

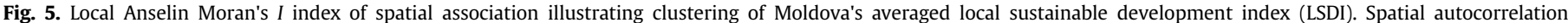
determined using queen contiguity of the 399 Thiessen polygons.

quality of education in rural and remote areas represents one of the greatest dissatisfactions among Moldavians. The 3rd MDG - promote gender equality and empower women - is double faceted in Moldova. There are no gender issues in the education system, while the labour market causes strong concerns about gender equality. To date, a timeframe for reaching this target remains uncertain. The 4th MDG - reduce child mortality - has shown the greatest progress among all the MDGs. The indicator of infant mortality and children under-5 mortality rate has already been reached. However, some important issues must be addressed in the post-2015 agenda. Specifically, decreasing child mortality gap between income classes and ethnic groups, as well as vaccinations within rural areas of 
Moldova.

The 5th MDG - improve maternal health - has already been achieved in Moldova. That said, there remain enormous regional differences with access and quality of medical services, especially in remote and rural areas. Vulnerable groups (e.g., Rroma, women, disabled persons) are most at risk to suffer from lack of quality medical services. Despite the decreasing trend in child mortality, maternal mortality rate has increased slightly from the 1990 to 2015 timeframe. The 6th MDG - combat HIV/AIDS, malaria and other diseases - has the most uncertain future because none of these have been halted. Due to governmental policies with limited financial backing, tuberculosis continues to spread in rural areas and HIV rates climb in urban areas.

The 7th MDG - ensure a sustainable environment - has shown some progress but additional efforts are required to reach all associated indicators. The indicator of state protected areas $(4.65 \%$ of national territory) was achieved in 2006. The formal condition has been respected, but creation of a proper environmental management system for these areas is still under way. Sewage systems are in the same situation, and in spite of their poor quality the formal target has been reached. The indicators related to forestland area proportion (12.1\%) and access to improved water supply systems have not been met. Improving access to improved water seems doable in the near future; however increasing the amount of core forest habitat seems unlikely under current land management practices. As with other MDGs, rural dwellers are most vulnerable with respect to MDG 7. The primary risks related to achieving this goal are related to environmental pollution, degrading population health, reduced crop productivity and land degradation. The 8th MDG - create a global partnership for development - has shown significant progress in some (non-policy) measures. Specifically, an increase in mobile phone, PCs, and Internet use has increased global awareness and communication between international groups.

\section{Conclusions}

'A concerted effort to enhance habitability of our planet is unlikely to succeed unless we know "where we are" and "where we want to go"' (Thomas, 1972). This paper provides the first comprehensive evaluation of sustainable development across the Republic of Moldova by fulfilling its three objectives. First, the local sustainable development index (LSDI) was created using household and property composition indicators primarily from a 2005 demographic and health survey for the Republic of Moldova (MDHS, 2006). This dataset's sample size and aggregated spatial reference was 11,066 households and 399 geographic locations, respectively. Moldova's LSDI used a 15 sub-metric optimum, equal weighting, 1-5 ordinal scale standardization, and additive construction. The 15 LSDI sub-metrics were illustrated to help decipher spatial patterns of sustainable development sub-themes. Second, Spearman's rank correlation coefficient (rho) correlation coefficient test $\left(r_{s}\right)$ was used to measure numerical dependence between LSDI metavariables. Collinearity results revealed a wealth sub-index had greatest redundancy with other sub-metrics. Third, the local index of spatial association (LISA) Anselin (1995) Moran's I-test was used to illustrate geographic patterns of LSDI. The spatial clustering results revealed that Moldova's improved sustainability levels are found primarily in large urban areas.

The processes of environmental quality, social equity, and economic welfare create unique geographic patterns that should not be viewed as homogeneous over space. Specifically, the findings herein are only for the Republic of Moldova at a specific time and spatial extent, and therefore should not be viewed as assignable to other locations. It is hoped that the findings of this study will aid in prioritizing sustainable development resources across Moldova. Note the intention of this research was not just to create another development index in a world of metric saturation. Rather, a major intention of this study was to provide a pragmatic, flexible, and transferable method that can be adapted to other countries for geographically analyzing and evaluating their local development patterns. This study does so by providing an uncomplicated methodology for capturing sustainability's 'triple bottom line' while remaining analytically sensitive and comprehensible.

It would be wrong to conclude that this study puts forth the only method for applied regional sustainable development assessment across a country. Only through the re-application of the LSDI framework found within this paper can confidence in its applicability be made. Due to the seriousness of developing world issues, it is hoped that readers of this manuscript will be motivated to create other applied approaches similar to the one outlined here to improve local sustainable development initiatives. Its outright rejection without provision of an alternative procedure useful for spatial assessment will only slow the progress of local sustainable development monitoring programs. In the developing world, the topic of making sustainable development operational needs to rise to the forefront of topics for scientists, planners, and policymakers. The proceeding research step would be to validate LSDI through different levels of community-based stakeholder evaluation. Next, after index corroboration, inferential relationships could be tested between various predictors and LSDI. Outside of this study, other research remains that examines relationships between policies, indicators, and sustainable development management practices. In closing, studies like this one help to provide tools for moving humanity towards its end goal of global sustainability.

\section{Acknowledgments}

The research within this article was made possible through the support of a J. William Fulbright Grant, United States Department of State. The Institute of Ecology and Geography, Academy of Sciences of Moldova provided additional resources needed. The authors would like to thank both agencies for making this international research opportunity possible. The findings and conclusions should not reflect on the supporting agencies.

\section{References}

Anselin, L. (1995). Local indicators of spatial association - LISA. Geographical Analysis, 27(2), 93-115.

Böhringer, C., \& Jochem, P. E. (2007). Measuring the immeasurable - a survey of sustainability indices. Ecological Economics, 63(1), 1-8.

Bossel, H. (1999). Indicators for sustainable development: theory, method, applications (p. 138). Winnipeg: International Institute for Sustainable Development.

Butchart, S. H., Walpole, M., Collen, B., van Strien, A., Scharlemann, J. P. W. Almond, R. E. A., et al. (2010). Global biodiversity: indicators of recent declines. Science, 328, 1164-1168.

Campbell, S. (1996). Green cities, growing cities, just cities?: urban planning and the contradictions of sustainable development. Journal of the American Planning Association, 62(3), 296-312.

Carruthers, G., \& Tinning, G. (2003). Where, and how, do monitoring and sustainability indicators fit into environmental management systems? Animal Production Science, 43(3), 307-323.

Clark, W., \& Dickson, N. M. (2003). Sustainability science: the emerging research program. PNAS, 100(14), 8059-8061.

Dormann, C. E., McPherson, J. M., Araújo, M. B., Bivand, R., Bolliger, J., Carl, G., et al. (2007). Methods to account for spatial autocorrelation in the analysis of species distributional data: a review. Ecography, 30, 609-628.

ESRI - Environmental Systems Research Institute. (2014). ArcGIS 10.2. Copyright 1999-2014. Redlands, CA: Computer Software.

Gerland, P., Raftery, A., Ševčíková, H., Li, N., Gu, D., Spoorenberg, T., et al. (2014). World population stabilization unlikely this century. Science, 346(6206), 234-237. http://dx.doi.org/10.1126/science.1257469.

Griggs, D., Stafford-Smith, M., Gaffney, O., Rockström, J., Öhman, M. C., Shyamsundar, P., et al. (2013). Policy: sustainable development goals for people and planet. Nature, 495(7441), 305-307. 
Grosskuth, J. (2007). Ambition and reality in modeling: a case study on public planning for regional sustainability. Sustainability: Science, Practice, \& Policy, 3(1), 3-11.

Hezri, A., \& Dovers, S. (2006). Sustainability indicators, policy and governance: issues for ecological economics. Ecological Economics, 60, 86-99.

Houghton, J. (2009). Global warming: The complete briefing. Cambridge University Press.

Hughes, B. B., \& Johnston, P. D. (2005). Sustainable futures: policies for global development. Futures, 37(8), 813-831.

Innes, J. E., \& Booher, D. E. (2000). Indicators for sustainable communities: a strategy building on complexity theory and distributed intelligence. Planning Theory \& Practice, 1(2), 173-186.

Jepson, E. J. (2004). Human nature and sustainable development: a strategic challenge for planners. Journal of Planning Literature, 19(1), 3-15.

Kates, R. W., Clark, W. C., Corell, R., Hall, J. M., Jaeger, C. C., Lowe, I., et al. (2001). Sustainability science. Science, 292, 641-642.

Keiner, M. (2006). The future of sustainability. Amsterdam, The Netherlands: Springer.

Legendre, P., \& Legendre, L. (2012). Numerical ecology (3rd ed.). Amsterdam, The Netherlands: Elsevier.

Lehman, A. (2005). JMP for basic univariate and multivariate statistics: A step-by-step guide. Cary, NC, USA: SAS Institute.

Maclaren, V. W. (1996). Urban sustainability reporting. Journal of the American Planning Association, 62(2), 184-202.

MDHS - Moldova Demographic and Health Survey 2005. (2006). National scientific and applied Center for preventative medicine (NCPM). [Moldova] and ORC macro. Calverton, Maryland, USA: National Scientific and Applied Center for Preventative Medicine of the Ministry of Health and Social Protection and ORC Macro [Internet]. [cited 2015 Jun 7]. Available from: http://pdf.usaid.gov/pdf_docs/ Pnadh788.pdf.

Morse, S., \& Fraser, E. D. (2005). Making ‘dirty' nations look clean? The nation state and the problem of selecting and weighting indices as tools for measuring progress towards sustainability. Geoforum, 36(5), 625-640.

Nation Report - National Report for UN CSD 2012 Rio +20. (2012). Chişinău, Republic of Moldova. 62p. [Internet]. [cited 2015 Jun 7]. Available from https:// sustainabledevelopment.un.org/content/documents/782Moldova_Report_ RIO20_ENG_12-06-2012_final.pdf.

Ness, B., Urbel-Piirsalu, E., Anderberg, S., \& Olsson, L. (2007). Categorising tools for sustainability assessment. Ecological economics, 60(3), 498-508.

Parris, T. M., \& Kates, R. W. (2003). Characterizing a sustainability transition: goals, targets, trends, and driving forces. PNAS, 100(14), 8068-8073.

Phillips, J. (2015). A quantitative approach to determine and evaluate the indicated level and nature of global ecological sustainability. Area, 47(2), 197-210.

Pollesch, N., \& Dale, V. H. (2015). Applications of aggregation theory to sustainability assessment. Ecological Economics, 114, 117-127.

Prescott-Allen, R. (2001). The well-being of nations: A country-by-country index of quality of life and the environment. Washington, DC: Island Press.

Reed, M. S., Dougill, A. J., \& Baker, T. R. (2008). Participatory indicator development: what can ecologists and local communities learn from each other. Ecological Applications, 18(5), 1253-1269.

Rogers, P., Jalal, K., \& Boyd, J. (2008). An introduction to sustainable development. Sterling, VA, USA: Glen Educational Foundation.

Rutstein, S. (1999). Wealth versus expenditure: Comparison between the DHS wealth index and household expenditures in four departments of Guatemala. Calverton, Maryland, USA: ORC Macro.
Rutstein, S. O., Johnson, K., \& Gwatkin, D. (2000). Poverty, health inequality, and its health and demographic effects. Paper presented at the 2000 Annual Meeting of the Population Association of America. Los Angeles: California, USA.

SAS - SAS Institute Incorporated. (2013). JMP TM system for statistics (Cary, NC. USA).

Shaker, R. R. (2015a). The spatial distribution of development in Europe and its underlying sustainability correlations. Applied Geography, 63, 304-314.

Shaker, R. R. (2015b). The well-being of nations: an empirical assessment of sustainable urbanization for Europe. International Journal of Sustainable Development \& World Ecology, 22(5), 375-387.

Shaker, R. R., \& Zubalsky, S. L. (2015). Examining patterns of sustainability across Europe: a multivariate and spatial assessment of 25 composite indices. International Journal of Sustainable Development \& World Ecology, 22(1), 1-13.

Singh, R. K., Murty, H. R., Gupta, S. K., \& Dikshit, A. K. (2012). An overview of sustainability assessment methodologies. Ecological Indicators, 15(1), 281-299.

Sirodoev, I. G. (2009). Cities and regional development in the Republic of Moldova. Elena-V.I.. Chișinău, Republic of Moldova. 50 p.

Stocker, T. F., Qin, D., Plattner, G. K., Tignor, M., Allen, S. K., Boschung, J.... Midgley, B. M. (2013). IPCC, 2013: climate change 2013: the physical science basis. In Contribution of working group I to the fifth assessment report of the intergovernmental panel on climate change.

Thomas, W. A. (1972). Indicators of environmental quality. New York, NY: Plenum Press.

Tobler, W. R. (1970). A computer movie simulating urban growth in the Detroit region. Economic Geography, 46, 230-240.

UN - United Nations. (2007). Indicators of sustainable development: Guidelines and methodologies (3rd ed.). New York (NY), USA: United Nations: Economic and Social Affairs. [Internet]. [cited 2015 Jun 7]. Available from http://www.un.org/ esa/sustdev/natlinfo/indicators/guidelines.pdf.

$\mathrm{UN}$ - United Nations. (2014). Concise report on the world population situation in 2014. Department of Economic and Social Affairs, Population Division. ST/ESA/ SER.A/354. 38 p. [Internet]. [cited 2015 Jun 7]. Available from http://www.un. org/en/development/desa/population/publications/pdf/trends/Concise\% 20Report\%20on\%20the\%20World\%20Population\%20Situation\%202014/en.pdf.

UN - United Nations. (1992). Agenda 21: The United Nations Programme of Action From Rio (United Nations, New York, NY, USA).

UNCSD - United Nations Conference on Sustainable Development. (2012). The future we want. New York (NY), USA: United Nations. [Internet]. [cited 2015 Jun 7]. Available from http://www.un.org/en/sustainablefuture/pdf/conf_brochure. pdf.

Vermeulen, S. J., Campbell, B. M., \& Ingram, J. S. (2012). Climate change and food systems. Annual Review of Environment and Resources, 37(1), 195.

WBG - World Bank Group. (2014). Ending poverty and sharing prosperity. Global Monitoring Report 2014/2015. Washington, DC, USA: A joint publication of the World Bank Group and the International Monetary Fund. [cited 6 July 2015]. Available from http://www.worldbank.org.

WCED - World Commission on Environment and Development. (1987). Our common future. Oxford, UK: Oxford University Press.

Weinzettel, J., Hertwich, E. G., Peters, G. P., Steen-Olsen, K., \& Galli, A. (2013). Affluence drives the global displacement of land use. Global Environmental Change, 23, 433-438.

Wilson, J., Tyedmers, P., \& Pelot, R. (2007). Contrasting and comparing sustainable development indicator metrics. Ecological Indicators, 7(2), 299-314.

$\mathrm{Wu}, \mathrm{J}$. (2008). Making the case for landscape ecology: an effective approach to urban sustainability. Landscape Journal, 27, 41-50. 